\title{
Montelukast and Budesonide for Childhood Cough Variant Asthma
}

\author{
Wu Sun 1 and Hai-Yan Liu²
}

\begin{abstract}
Objective: To determine the effects of combined treatment of montelukast and budesonide on young children with cough variant asthma, and their serum inflammatory factors of serum hypersensitive c-reactive protein (hs-CRP), tumour necrosis factor- $\alpha$ (TNF- $\alpha$ ), interleukin-6 (IL-6) and pulmonary function.

Study Design: An experimental study.

Place and Duration of Study: The Second Affiliated Hospital of Xi'an Jiaotong University, China, from January 2016 to January 2017.

Methodology: A total of 112 children with cough variant asthma were randomly divided into observation group and control group with 56 cases in each group. All children were treated with antibiotics and resolving phlegm. The control group were given budesonide, while the observation group was treated additionally with montelukast. After the course, improvement time of clinical symptoms of cough, asthma, etc., changes in levels of serum inflammatory factors of hs-CRP, TNF- $\alpha$ and IL-6, and pulmonary function indexes of forced vital capacity (FVC), forced expiratory volume at the end of the first 1s $\left(F E V_{1}\right)$, peak expiratory flow $(P E F)$, and observe concurrence of untoward effects in the two groups of sick children were compared.

Results: After treatment, extinction time for cough and for asthma of the observation group was less than those in the control group (all p<0.001). Levels of serum hs-CRP, TNF- $\alpha$, IL- 6 in the observation group were all lower than those of the control group (all $p<0.001$ ). Pulmonary function indices of FVC, FEV1 and PEF of the two groups of sick children were all higher than those of the control group (all $p<0.001$ ). During the treatment, there was no difference in the comparison of untoward effect rate of the two groups $(p=0.696)$. After follow-up observation on the two groups of sick children for 1 year, the recurrence rate of the observation group was lower than that of the control group $(p=0.026)$.

Conclusion: Curative effects on young children with cough variant asthma of montelukast combined with budesonide are significant. The therapy may improve clinical symptoms and pulmonary function and reduce serum inflammatory factor level of sick children, with high application value and worthy of application and promotion.
\end{abstract}

Key Words: Children with cough variant asthma, Montelukast, Budesonide, Pulmonary function, hs-CRP, TNF- $\alpha$, IL-6.

\section{INTRODUCTION}

Cough variant asthma (CVA) is also called allergic cough, with the main symptom of cough. Main clinical characteristics: Cough continuously for more than four weeks, break out at night (or) in the early morning frequently, worsen after exercises, meeting cold air or special smells; less phlegm and no obvious infection sign. ${ }^{1,2}$ Most scholars believe that CVA is a kind of airway chronic allergic inflammation participated by multiple inflammatory cells, with the characteristic of airway hyper-responsiveness. Inflammatory cells release inflammatory mediators, which cause airway chronic nonspecific inflammation; If there is only hyperresponsiveness in the airway and no spasm, stenosis or there are slight changes, the clinical features are continuous, repeated cough and no typical asthma gasp. 3,4 CVA is often misdiagnosed as bronchial asthma,

1 Guangyuan City Maternal and Child Health Hospital Children's Health Hospital, Guang Yuan, 628000, China

2 The Second Affiliated Hospital of Xi'an Jiaotong University, Xi'an, 710004, China

Correspondence: Hai-Yan Liu, The Second Affiliated Hospital of Xi'an Jiaotong University, Xi'an Shaanxi, 710004, China E-mail:byi2tz@163.com

Received: April 14, 2018; Accepted: October 29, 2018 which not only delays clinical treatments, but also makes the condition persistent and recurrent, and is adverse to growth and development of sick children. 5

At present, for sick children with CVA, the clinic proposes to adopt combined treatment of glucocorticoid and leukotriene receptor antagonist. ${ }^{6}$ Budesonide is a kind of glucocorticoid drug, whose efficiency has been generally recognized by clinicians, but glucocorticoid has inhibiting effect not on all inflammatory factors, especially less on leukotriene. ${ }^{7}$ Montelukast is a common leukotriene receptor antagonist clinically, which can inhibit release and activity of leukotriene effectively. ${ }^{8}$

The objective of this study was to determine curative effects of combined treatment of montelukast and Budesonide on young children with cough variant asthma, and discuss its influence on patents' serum inflammatory factors of serum hypersensitive c-reactive protein (hs-CRP), tumour necrosis factor- $\alpha$ (TNF- $\alpha$ ), interleukin-6 (IL-6), and pulmonary function.

\section{METHODOLOGY}

This study was conducted at The Second Affiliated Hospital of Xi'an Jiaotong University, China, from January 2016 to January 2017. Selected 112 cases were children with cough variant asthma as research objects. Inclusion 
criteria were children who conformed to the diagnostic criteria of CVA, and the blood routine and chest X-ray examination of sick children are normal. Exclusion criteria were chronic cough caused by other reasons, coexistent other infectious diseases, and children not taking the research medicines recently or allergic to them. The study was conducted after approval from the Hospital Ethical and Research Committee.

The 112 cases of sick children were randomly divided into the observation group and the control group, with 56 cases in each group.

After admission, the two groups of sick children were all treated properly with oxygen inhalation, antibiotics, cough relieveing, sputum reducetis and asthma controlling measures/agents, etc. In addition to this, the control group was given added aerosol budesonide, $1 \mathrm{mg} /$ once, twice/day. The observation group was treated additionally with montelukast chewing tablet, $4 \mathrm{mg} /$ once for children $\leq 5$ years, $5 \mathrm{mg} /$ once for children $\geq 6$ years, oral before sleep once/day. The two groups treated for continuous two months.

After the course of treatment finished, improvement time of clinical symptoms and extinction time of cough and asthma was compared; PF and PEF detectors were adopted to examine and compare pulmonary function indexes of forced vital capacity (FVC), forced expiratory volume at the end of first $1 \mathrm{~s}\left(\mathrm{FEV}_{1}\right)$ and peak expiratory flow (PEF) of the two groups. ELISA method was used for examining indexes of serum hs-CRP, TNF- $\alpha$, IL- 6 of the two groups. Occurrence of untoward effects of drowsiness, dizziness, headache and gastrointestinal reaction, etc. were also observed and compared. After treatment, follow-up observation was carried out on the two groups of children for a year, to collect and compare their recurrence spisodes.

Data was analysed in SPSS version 25. Mean value \pm SD was calculated for numericals like extinction time for cough, levels of serum hs-CRP, TNF- $\alpha$, IL-6. Pulmonary function indices were examined by independent sample t-test. Frequencies and percentages were calculated for categorical variables like gender, untoward effects and recurrence situations. Chi-square test was applied to compare the categorical variables in two groups. P-value of less than or equal to 0.05 was considered statistically significant.

\section{RESULTS}

There were $70(62.50 \%)$ boys and $42(37.50 \%)$ girls, with age of $3-10(7.51 \pm 0.82)$ years and course of disease of 1-3 (1.51 \pm 0.63$)$ years.

After treatment, extinction time for cough of sick children in the observation group was $7.14 \pm 0.47$ days vs. 9.48 \pm 1.28 days of the control group $(p<0.001)$; extinction time for asthma of sick children in the observation group was $8.16 \pm 2.13$ days vs. $10.02 \pm 2.56$ days of the control group $(p<0.001)$.

After treatment, levels of serum hs-CRP, TNF- $\alpha$, IL-6 in the observation group were all lower than those of the control group (all $p<0.001$, Table I). Pulmonary function indices of FVC, FEV 1 and PEF of the two groups of sick children were all higher than those of the control group (all $p<0.001$, Table II).

During the treatment, the occurrence rate of untoward effects of dizziness, drowsiness and gastrointestinal reaction in the observation group was $5.36 \%$ (3 cases), lower than $7.14 \%$ (4 cases) of the control group, but there was no difference in the comparison of untoward effect rate of the two groups $(p=0.696)$. After follow-up observation on the two groups of sick children for 1 year, the recurrence rate of the observation group was $3.57 \%$ (2 cases), lower than $16.07 \%$ (9 cases) of the control group $(p=0.026$, Table III).

\section{DISCUSSION}

Pathogenesis of CVA is thought to be quite similar to asthma. The pathological-physiological adaptations are

Table I: Comparison of serum inflammatory factor level of the two groups after treatment.

\begin{tabular}{|c|c|c|c|c|c|c|c|}
\hline \multirow[t]{2}{*}{ Groups } & \multirow[t]{2}{*}{$\mathrm{n}$} & \multicolumn{2}{|c|}{ hs-CRP (mg/L) } & \multicolumn{2}{|c|}{ TNF- $\alpha$ (ng/L) } & \multicolumn{2}{|c|}{ IL-6 (ng/L) } \\
\hline & & Mean \pm SD & $p$-value & Mean \pm SD & $p$-value & Mean \pm SD & $\mathrm{p}$-value \\
\hline Control group & 56 & $15.62 \pm 2.04$ & $<0.001$ & $487.35 \pm 34.11$ & $<0.001$ & $44.23 \pm 1.71$ & $<0.001$ \\
\hline Observation group & 56 & $13.63 \pm 1.54$ & & $402.92 \pm 21.32$ & & $37.85 \pm 2.98$ & \\
\hline
\end{tabular}

Table II: Comparison of pulmonary function indexes of the two groups after treatment.

\begin{tabular}{|c|c|c|c|c|c|c|c|}
\hline \multirow[t]{2}{*}{ Groups } & \multirow[t]{2}{*}{$\mathrm{n}$} & \multicolumn{2}{|c|}{$\mathrm{FVC}(\mathrm{L})$} & \multicolumn{2}{|c|}{ FEV1 (L) } & \multicolumn{2}{|c|}{$\mathrm{PEF}(\mathrm{L} / \mathrm{s})$} \\
\hline & & Mean $\pm S D$ & $p$-value & Mean \pm SD & $p$-value & Mean \pm SD & p-value \\
\hline Control group & 56 & $3.04 \pm 0.43$ & $<0.001$ & $2.42 \pm 0.18$ & $<0.001$ & $2.96 \pm 0.58$ & $<0.001$ \\
\hline Observation group & 56 & $3.96 \pm 0.40$ & & $3.09 \pm 0.31$ & & $3.81 \pm 0.51$ & \\
\hline
\end{tabular}

Table III: Comparison of untoward effects and recurrence situations of the two groups.

\begin{tabular}{|c|c|c|c|c|c|c|c|c|}
\hline Groups & $\mathrm{n}$ & $\begin{array}{c}\text { Dizziness } \\
{[\mathrm{n}(\%)]}\end{array}$ & $\begin{array}{l}\text { Drowsiness } \\
{[\mathrm{n}(\%)]}\end{array}$ & $\begin{array}{r}\text { Gastrointestinal } \\
\text { reaction }[\mathrm{n}(\%)]\end{array}$ & $\begin{array}{c}\text { Untoward effect } \\
\text { rate }[\mathrm{n}(\%)]\end{array}$ & $\mathrm{p}$-value & $\begin{array}{c}\text { Recurrence rate } \\
{[\mathrm{n}(\%)]}\end{array}$ & $p$-value \\
\hline Control group & 56 & $1(1.79)$ & $1(1.79)$ & $2(3.57)$ & $4(7.14)$ & 0.696 & $9(16.07)$ & 0.026 \\
\hline Observation group & 56 & $1(1.79)$ & $1(1.79)$ & $1(1.79)$ & $3(5.36)$ & & $2(3.57)$ & \\
\hline
\end{tabular}


a sustained airway inflammation and airway hyperresponsiveness; and infection, inheritance, environment, physical, and chemical factors cause the disease. Viral infection results in injuries of airway tissues, and makes the vagus fibres exposed and cholinergic nerve fibrosis sensitized. Once being stimulated, it will cause reflectivity enhancement of bronchial smooth muscles and partial tracheole shrink, which will stimulate ending cough receptor, and cause cough reflex directly. But there is no symptom and sign of gasp, so it becomes variant asthma with main feature of cough.9,10

Glucocorticoids are effective on treating children with CVA, and remit clinical symptoms by inhibiting the airway inflammation. ${ }^{11,12}$ As the new generation of glucocorticoids with high efficiency, budesonide can enhance the stability of membranes, reduce synthesis and release of allergenic mediums such as histamine and decline its activity by interdicting metabolism of arachidonic acid. It can also reduce synthesis and release of vasoexcitor materials by inhibiting enzymatic reactions of antigen antibody combination, to inhibit smooth muscle shrink and relieve airway hyperresponsiveness. ${ }^{13-15}$ Besides, budesonide is used in aerosol form, whose absorbance and availability are higher, leading to better tolerance of sick children. However, some scholar reports that budesonide cannot relieve organic inflammatory response mediated by leukotrienes. ${ }^{16}$ As an important inflammatory medium inducing CVA, leukotrienes can promote shrink of bronchial smooth muscle and glandular secretion of airway mucosa to cause diseases by increasing vascular permeability. 17 Montelukast is leukotriene receptor antagonist, with high selectivity and specificity. After combining with leukotriene receptor, it can relieve bronchospasm and airway mucosal edema, and reduce inflammatory cell infiltration and mucus secretion, thus decline airway hyper-reactivity and promote asthma symptom and improvement of pulmonary function. 18 Sick children in the observation group adopt combined treatment of montelukast and budesonide. The result showed that extinction time of cough and asthma of sick children was less, and improvement of pulmonary function indexes of FVC, $\mathrm{FEV}_{1}$ and PEF was more obvious. This conclusion is consistent with previous reports. $19 \mathrm{It}$ is probably because combined treatment of montelukast and budesonide can make up their limitations, and take synergistic effect, resulting in improving asthmatic attack symptoms and promote recovery of pulmonary function.

Studies find that key causes-induced airway chronic inflammation are plenty of inflammatory mediums secreted by T-lymphocytes and mastocytes. 20 Inflammatory level of hs-CRP, TNF- $\alpha$ and IL- 6 in patients' serum rises obviously, in which TNF- $\alpha$ plays an important role, by releasing more oxygen-free radical and activating inflammatory cells to release more inflammatory factors. hs-CRP is a kind of acute phase reaction protein, which is regarded as one of the most sensitive inflammatory indexes. ${ }^{21}$ Relevant data shows, except reflecting the inflammatory level of lower respiratory tract, hs-CRP's level shows significant correlation with the airflow limitation of chronic obstructive pulmonary patients. 22 Namely, the airflow limitation is severer, the hs-CRP level is higher. IL-6 is a kind of cell factor with multiple biological activities, produced by secretion of lymphocytes and multiple nonlymphocytics. It can activate neutrophile granulocytes, delay phagocytosis of phagocytes to neutrophile granulocytes and promote oxidizing reaction of neutrophile granulocytes. ${ }^{23}$ Results of this research showed that serum hs-CRP, TNF- $\alpha$ and IL- 6 level of the two groups of sick children were all reduced after treatment, but reduction of the above serum inflammatory factor level in the observation group was more obvious. This proves that combined treatment of montelukast and budesonide have advantages on the aspect of improving airway inflammatory reactions of sick children with CVA.

The untoward effect rates of both groups were lower, but there was no statistical significance in the difference. Recurrence rate was obviously lower in the observation group. It is probably because airway inflammatory reaction gets better control; and airway hypersensitivity also reduces after level of serum inflammatory factors reduces, thus prognosis of sick children is improved. Aerosol makes budesonide reach the affected tissues directly in the form of particles, which can maintain the focus with higher concentration, taking effect faster. Meanwhile, topical treatment requires less dose, so safety is also improved. Oral montelukast extends the action time, thus making the therapeutic schedule achieves the purpose of fast action, strong effect, and long subsistence. Combined treatment of montelukast and budesonide on children CVA has significant effects and synergistic actions, worthy of promotion.

\section{CONCLUSION}

Curative effects on young children with cough variant asthma of montelukast combined with budesonide are significant. The therapy may improve clinical symptoms and pulmonary function and reduce serum inflammatory factor level of sick children, with high application value and worthy of application and promotion.

Acknowledgement: This study was supported by General Program of Science and Technology Department Foundation of Shaanxi Province, China (Grant No. 2007K15-01(15).

\section{REFERENCES}

1. Song WJ, Kim HJ, Shim JS, Won HK, Kang SY, Sohn K H, et al. Diagnostic accuracy of fractional exhaled nitric oxide measurement in predicting cough-variant asthma and eosinophilic 
bronchitis in adults with chronic cough: A systematic review and meta-analysis. J Allergy Clin Immunol 2017; 140:701-9.

2. Li W, Ban C, Zhang J, Hu Y, Han B, Han B. Correlation study of cough variant asthma and mycoplasma pneumonia infection in children. Pak J Pharm Sci 2017; 30:1099-102.

3. De Diego A, Martínez E, Perpiñá M, Nieto L, Compte L, Macián V, et al. Airway inflammation and cough sensitivity in coughvariant asthma. Allergy 2005; 60:1407-11.

4. Kanemitsu Y, Niimi A, Matsumoto H, Iwata T, Ito I, Oguma T, et al. Gastroesophageal dysmotility is associated with the impairment of cough-specific quality of life in patients with cough variant asthma. Allergol Int 2016; 65:320-6.

5. Wang X, Liu B, Lu B, Zhang Y, Wang L, Li H, et al. Microinvasive embedding combined with montelukast sodium for children cough variant asthma: a randomized controlled trial. Zhongguo Zhen Jiu 2017; 37:259-64.

6. Leickmaldonado EA, Kay FU, Leonhardt MC, Kasahara DI, Prado CM, Fernandes FT, et al. Comparison of glucocorticoid and cysteinyl leukotriene receptor antagonist treatments in an experimental model of chronic airway inflammation in guineapigs. Clin Exp Allergy 2004; 34:145-52.

7. Von Arnim U, Malfertheiner P. Eosinophilic esophagitis-treatment of eosinophilic esophagitis with drugs: corticosteroids. Dig Dis 2014; 32:126-9.

8. Haque I, Ravikumar, Narayanaswamy VB, Hoque M. Formulation and evaluation of montelukast sodium fast dissolving tablets. Asian J Biomed Pharm Sci 2016; 6:159-69.

9. Koh YY, Kang H, Yoo Y, Kim DK, Yu J, Kim KK. Wheeze detection as a measure of bronchial challenge in young children with cough-variant asthma and with classic asthma. Acta Paediatr 2007; 96:1223-7.

10. Yuan J, An SH, Gao WJ, Du WJ, Sun JF, Zhang M, et al. Comparative analysis of conventional pulmonary function test results in children with asthma or cough variant asthma. Zhongguo Dang Dai Er Ke Za Zhi 2013; 15:171-4.

11. Taff CC, Schoenle LA, Vitousek MN. The repeatability of glucocorticoids: A review and meta-analysis. Gen Comp Endocrinol 2018; 260:136-45.

12. Mazziotti G, Giustina A, Canalis E, Bilezikian JP. Treatment of glucocorticoid-induced osteoporsis. Ther Adv Musculoskelet Dis 2009; 1:27-34.
13. Acun C, Tomac N, Ermis B, Onk G. Effects of inhaled corticosteroids on growth in asthmatic children: A comparison of fluticasone propionate with budesonide. Allergy Asthma Proc 2005; 26:204-6.

14. Albert D, Heifert TA, Min SB, Maydonovitch CL, Baker TP, Chen YJ, et al. Comparisons of fluticasone to budesonide in the treatment of eosinophilic esophagitis. Dig Dis Sci 2016; 61:1996-2001.

15. Münch A, Bohr J, Miehlke S, Benoni C, Olesen M, Åke Öst, et al. Low-dose budesonide for maintenance of clinical remission in collagenous colitis: A randomised, placebocontrolled, 12-month trial. Gut 2016; 65:47-56.

16. Crisafulli E, Guerrero M, Menéndez R, Huerta A, Martinez R, Gimeno A, et al. Inhaled corticosteroids do not influence the early inflammatory response and clinical presentation of hospitalized subjects with copd exacerbation. Respir Care 2014; 59:1550-9.

17. Lotufo CM, Yamashita CE, Farsky SH, Markus RP. Melatonin effect on endothelial cells reduces vascular permeability increase induced by leukotriene B4. Eur J Pharmacol 2006; 534:258-63.

18. Sook PJ, Soo JA, Woo PS, Mok LY, Taek US, Hoon KY, et al. Protection of leukotriene receptor antagonist against aspirininduced bronchospasm in asthmatics. Allergy Asthma Immunol Res 2010; 2:48-54

19. Wang XP, Yang LD, Zhou JF. Montelukast and budesonide combination for children with chronic cough-variant asthma. Medicine (Baltimore) 2018; 97:e11557.

20. Brill A, Baram D, Sela U, Salamon P, Mekori YA, Hershkoviz R. Induction of mast cell interactions with blood vessel wall components by direct contact with intact $\mathrm{T}$ cells or $\mathrm{T}$ cell membranes in vitro. Clin Exp Allergy 2004; 34:1725-31.

21. Ucar SK, Coker M, Sözmen E, Simsek DG, Darcan S. A monocentric pilot study of an antioxidative defense and hscrp in pediatric patients with glycogen storage disease type IA and III. Nutr Metab Cardiovasc Dis 2009; 19:383-90.

22. Gläser S, Ittermann T, Koch B, Völzke H, Wallaschofski $H$, Nauck $\mathrm{M}$, et al. Airflow limitation, lung volumes and systemic inflammation in a general population. Eur Respir J 2012; 39 29-37.

23. Yu EW, Dolter KE, Shao LE, Yu J. Suppression of IL-6 biological activities by activin $A$ and implications for inflammatory arthropathies. Clin Exp Immunol 1998; 112:126-32. 